\title{
PENGGUNAAN TANAMAN OBAT TRADISIONAL UNTUK MENINGKATKAN NAFSU MAKAN PADA BALITA
}

\author{
Ari Kurniarum, Rizky Ayu Novitasari \\ Kementerian Kesehatan Politeknik Kesehatan Surakarta Jurusan Kebidanan
}

\begin{abstract}
Use of Traditional Medicinal Plants, Appetite, Toddler. Causes of malnutrition in children under five is no appetite, then the parents use alternative to traditional medicinal plants. The purpose of this study was fatherly to know the use of traditional medicinal plants to improve appetite in infants. Quantitative descriptive research study subjects were women who use traditional medicinal plants to improve appetite in infants by 36 samples. The statistical test used this research is descriptive test. The results showed that the majority of children experiencing increasing appetite after the use of traditional medicinal plants.
\end{abstract}

Keywords: Use of Traditional Medicinal Plants, Appetite, Toddler

Abstrak: Penggunaan Tanaman Obat Tradisional, Nafsu Makan, Balita. Penyebab gangguan gizi pada balita adalah tidak nafsu makan, maka orangtua menggunakan alternatif tanaman obat tradisional. Tujuan penelitian ini adalah unutk mengetahui penggunaan tanaman obat tradisional untuk meningkatkan nafsu makan pada balita. Jenis penelitian deskriptif kuantitatif dengan subyek penelitian adalah ibu yang menggunakan tanaman obat tradisional untuk meningkatkan nafsu makan pada balita sebesar 36 sampel. Uji statistik yang digunakan penelitian ini adalah uji deskriptif. Hasil penelitian menunjukkan bahwa mayoritas balita mengalami peningkatkan nafsu makan setelah menggunakan tanaman obat tradisional.

Kata Kunci: Penggunaan Tanaman Obat Tradisional, Nafsu Makan, Balita

\section{PENDAHULUAN}

Penyebab langsung gangguan gizi khususnya pada bayi dan balita adalah tidak sesuainya jumlah gizi yang mereka peroleh dari makanan dengan kebutuhan tubuh mereka. Ketidak sesuaian ini salah satunya disebabkan karena susah makan yang merupakan dampak dari tidak nafsu makan. ${ }^{1}$ yang dimaksud dengan Balita atau Bawah Lima Tahun adalah semua anak termasuk bayi yang baru lahir, yang berusia 0 sampai menjelang 5 tahun (4 tahun, 11 bulan, 29 hari). Setiap orangtua pasti melakukan berbagai upaya agar kebutuhan gizi anak dapat tercukupi dengan baik, salah satunya dengan meningkatkan nafsu makan. Ada berbagai cara untuk meningkatkan nafsu makan pada balita mulai dari suasana makan yang dibuat nyaman, variasi dan bentuk makanan yang dibuat semenarik mungkin hingga penggunaan obat modern maupun obat tradisional.

Obat tradisional adalah bahan atau ramuan bahan yang berupa tumbuhan, bahan hewan, bahan mineral, sediaan sarian (galenik) atau campuran bahan tersebut yang secara turun temurun telah digunakan untuk pengobatan berdasarkan pengalaman. Faktor-Faktor yang mempengaruhi kecenderungan penggunaan tanaman obat tradisional.

1. Pengalaman pribadi

Pengalaman mengenai efektivitas dan efek samping tanaman obat tradisional telah banyak dirasakan oleh masyarakat.

2. Pendidikan 
Pendidikan diukur berdasarkan lamanya waktu yang dipergunakan seseorang dalam menempuh pendidikan formal. Proporsi penggunaan tanaman obat tradisional menurun dengan meningkatnya pendidikan responden.

3. Pendapatan ekonomi

Bupati Klaten memutuskan besaran Upah Minimum Kabupaten (UMK) 2014 senilai Rp1.026.000. Besaran UMK 2014 yang diputuskan Bupati tersebut lebih tinggi Rp10.741 dibandingkan dengan hasil survei Kehidupan Hidup Layak (KHL) di Klaten senilai Rp1.015.259. Semakin rendahnya pendapatan keluarga semakin tinggi penggunaan tanaman obat tradisional, hal ini dikarenakan harga tanaman obat tradisional lebih murah, bahannya yang mudah didapati disekitar lingkungan tempat tinggal dan cara pengolahannya tidak rumit, sehingga dapat dibuat didapur sendiri tanpa memerlukan peralatan yang khusus dan biaya yang besar.

4. Pekerjaan

Pekerjaan terdiri dari bekerja dan tidak bekerja. Bekerja apabila subjek penelitian memiliki kegiatan rutin yang dilakukan dirumah/ diluar rumah yang menghasilkan imbalan materi maupun uang. Sedangkan tidak bekerja apabila subjek penelitian tidak memiliki kegiatan rutin yang dilakukan dirumah/ di luar rumah yang menghasilkan imbalan materi maupun uang. Proporsi penggunaan pada responden yang mempunyai pekerjaan petani, nelayan dan tidak bekerja lebih tinggi daripada responden dengan pekerjaan lainnya.

\section{Sosial dan budaya.}

Obat tradisional merupakan salah satu sumber daya yang sudah ada sejak dahulu kala dimanfaatkan oleh nenek moyang kita dalam upaya mengatasi masalah kesehatan dengan menjadikan berbagai ramuan bahan tanaman obat.

Jenis Tanaman Obat Tradisional yang Berkhasiat Meningkatkan Nafsu Makan

1. Temulawak (Curcuma xanthorhiza) Secara praklinik dan klinik telah ditemukan bahwa rimpang temulawak dapat meningkatkan/ memperbaiki nafsu makan. Manfaat ini berkaitan dengan kerja karminativum dari minyak atsiri yang terkandung didalamnya.

2. Temu Hitam (Curcuma aeruginosa)

Kandungan dalam temu hitam antara lain Minyak atsiri, damar, pati dan lemak.

3. Temu Kunci (Boesenbergia pandurata) Rimpang temu kunci mengandung $1,2 \%$ minyak atsiri.

4. Lengkuas (Alpinia galanga)

Lengkuas mengandung senyawa kimia antara lain minyak atsiri, minyak terbang, eugenol, seskuiterpen, pinen, metil sinamat, kaemferida, galangan, galangol dan kristal kuning.

5. Kunyit (Curcuma Domestica)

Kunyit mengandung senyawa kimia antara lain minyak atsiri ( seskuiterpen alkohol, turmeron dan zingiberen), kurkuminoid (kurkumin, desmetoksi kurkumin dan bisdesmetoksi kurkumin), pati, gom dan getah.

6. Jahe (Zingiber Officinale)

Jahe mengandung minyak atsiri zingiberena (Zingirona), Zingiberol, Bisabolena, Kurkumen, Gingerol, Filandrena dan Resin pahit.

7. Pepaya (Carica Papaya)

Daun pepaya mengandung carposide, akar dan getah pepaya mengandung zat papiyotin, karpain, kautsyuk, karposit dan vitamin.

8. Brotowali (Tinospora crispa meir)

9. Tomat (Gycopersicum esculentum)

Khaisat tomat menambah nafsu makan dengan cara memperbanyak keluarnya air liur, merangsang keluarnya enzim 
lambung, dan melancarkan aliran empedu ke usus.

10. Adas (Foeniculum Vulgare Mill)

Kandungan kimianya antara lain minyak atsiri 1-6\%, mengandung 50$60 \%$ anetol, $\pm 20 \%$ fenkon, pinen, limonen, dipenten, feladren, metilchavikol, anisaldehid, asam anisat, dan $12 \%$ minyak lemak.

Sediaan Obat Tradisional

\section{Simplisia}

Bahan alamiah berupa tanaman utuh, bagian tanaman atau eksudat tanaman yang digunakan sebagai obat dan belum mengalami pengolahan atau mengalami pengolahan secara sederhana.

2. Serbuk

Serbuk adalah sediaan obat tradisional berupa butiran homogen dengan derajat halus yang cocok, bahan bakunya berupa simplisia, sediaan galenik atau campurannya.

3. Pil

Pil adalah sediaan padat obat tradisional berupa massa bulat, bahan bakunya berupa serbuk simplisia, sediaan galenik, atau campurannya.

4. Kapsul

Kapsul adalah sediaan obat tradisional yang terbungkus cangkang keras atau lunak, bahan bakunya terbuat dari sediaan galenik dengan atau tanpa bahan tambahan.

5. Tablet

Tablet adalah sediaan obat tradisional padat kompak, dibuat secara kempa cetak, dalam bentuk tabung pipih, silindris, atau bentuk lain, kedua permukaannya rata atau cembung, terbuat dari sediaan galenik dengan atau tanpa bahan tambahan.

6. Cairan obat dalam

Cairan obat dalam adalah sediaan obat tradisional berupa larutan emulsi atau suspense dalam air, bahan bakunya berasal dari serbuk simplisia atau sediaan galenik dan digunakan sebagai obat dalam.

\section{METODE PENELITIAN}

Desain penelitian ini menggunakan desain penelitian deskriptif kuantitatif. Penelitian deskriptif adalah penelitian yang dilakukan untuk mendeskripsikan atau menggambarkan suatu fenomena yang terjadi di dalam masyarakat. ${ }^{11}$ Kuantitatif adalah data yang diapaparkan dalam bentuk angka-angka.

Populasi yang digunakan dalam penelitian ini adalah ibu yang memiliki anak berusia 24-59 bulandi Desa Baran, Kecamatan Cawas, Kabupaten Klaten yaitu sejumlah 69 orang. Teknik pengambilan sampel yang digunakan dalam penelitian ini adalah purposive sampling dengan kriteria inklusi ibu yang anaknya pernah dan atau sedang mengalami gangguan nafsu makan dan menggunakan tanaman obat tradisional untuk meningkatkan nafsu makan pada anaknya. Sedangkan kriteria eksklusi antaralain ibu yang sakit hingga tidak sanggup/ tidak bisa mengisi kuisioner dan ibu yang tidak ada ditempat selama pengumpulan data dilakukan, maka diperoleh sampel sebanyak 36 responden.

Jenis data yang digunakan dalam penelitian ini adalah data primer. Cara pengumpulan data yang dilakukan dalam penelitian ini adalah dengan menggunakan instrumen penelitian berupa kuesioner tertutup dimana jawaban sudah disediakan sehingga responden tinggal memilih jawaban yang sesuai.

Analisa data dalam penelitian ini yaitu menggunakan Metode analisa data dalam penelitian adalah analisis data secara deskriptif menghasilkan tabel distribusi frekuensi dan persentase dari variabel penelitian. maka digunakan rumus :

$$
\begin{gathered}
P=\frac{f}{n} \times 100 \% \\
\text { Keterangan : } \\
\mathrm{P}=\text { persentase }
\end{gathered}
$$


$\mathrm{f}=$ frekuensi

$\mathrm{n}=$ jumlah responden

Dalam penyajian ini dibahas mengenai penggunaan tanaman obat tradisional beserta karakteristiknya, jenis tanaman obat tradisional yang digunakan ibu untuk meningkatkan nafsu makan balita, penggunaan bentuk sediaan tanaman obat tradisional untuk meningkatkan nafsu makan pada balita beserta karakteristiknya dan reaksi balita yang menggunakan tanaman obat tradisional untuk meningkatkan nafsu makan.

\section{HASIL PENELITIAN}

1. Karakteristik Responden

a. Pekerjaan

Dari 36 responden menunjukkan bahwa mayoritas ibu tidak bekerja yaitu sebanyak 22 responden $(61,1 \%)$.

\section{Tabel 1}

Karakteristik responden berdasarkan pekerjaan di Wilayah Desa Baran, Cawas, Klaten.

\begin{tabular}{llcc}
\hline No & Pekerjaan & $\begin{array}{c}\text { Jumlah } \\
\text { Responden }\end{array}$ & $\begin{array}{c}\text { Persentase } \\
(\%)\end{array}$ \\
\hline 1. & Bekerja & 14 & 38,9 \\
2. & Tidak & 22 & 61,1 \\
& Bekerja & & \\
\hline & Total & 36 & 100,0 \\
\hline
\end{tabular}

b. Pendapatan ekonomi

Menurut Upah Minimum Regional (UMR) Kabupaten Klaten tahun 2014 menunjukkan bahwa dari 36 responden mayoritas memiliki pendapatan ekonomi dibawah UMR yaitu <Rp.1.026.000 sebanyak 26 responden $(72,2 \%)$.

\section{Tabel 2}

Karakteristik responden berdasarkan pendapatan ekonomi di Wilayah Desa Baran, Cawas, Klaten

\begin{tabular}{|c|c|c|c|}
\hline No & $\begin{array}{l}\text { Pendapatan } \\
\text { (UMR) }\end{array}$ & $\begin{array}{c}\text { Jumlah } \\
\text { Responden }\end{array}$ & $(\%)$ \\
\hline 1. & < Rp.1.026.000,- & 26 & 72,2 \\
\hline 2. & $\geq$ Rp.1.026.000,- & 10 & 27,8 \\
\hline & Total & 36 & 100,0 \\
\hline
\end{tabular}

2. Jenis tanaman Tradisional
Tanaman obat tradisional yang paling banyak digunakan untuk meningkatkan nafsu makan pada balita umur (24-59) bulan adalah temu hitam yaitu sebanyak 22 responden $(61,1 \%)$.

Tabel 3

Jenis tanaman obat tradisional yang digunakan responden di Wilayah Desa Baran, Cawas, Klaten.

\begin{tabular}{clcc}
\hline No & Jenis Tanaman & $\begin{array}{c}\text { Jumlah } \\
\text { Responden }\end{array}$ & $(\%)$ \\
\hline 1. & Temulawak & 16 & 44,4 \\
2. & Temu hitam & 22 & 61,1 \\
3. & Temu Kunci & 0 & 0 \\
4. & Lengkuas & 0 & 0 \\
5. & Kunyit & 11 & 30,5 \\
6. & Jahe & 8 & 22,2 \\
7. & Pepaya & 17 & 47,2 \\
8. & Brotowali & 13 & 36,1 \\
9. & Tomat & 9 & 25,0 \\
10. & Adas & 0 & 0 \\
\hline
\end{tabular}

3. Bentuk Sediaan Tanaman Obat Tradisional

Bentuk sediaan tanaman obat tradisional yang paling banyak digunakan untuk meningkatkan nafsu makan pada balita umur (24-59) bulan adalah simplisia yaitu 27 responden $(75 \%)$.

Tabel 4

Bentuk sediaan tanaman obat tradisional yang digunakan responden di Wilayah Desa Baran, Cawas, Klaten. 4. Penggunaan Bentuk Sediaan Tanaman

\begin{tabular}{llcccc}
\hline No. & $\begin{array}{l}\text { Bentuk } \\
\text { Sediaan }\end{array}$ & Bekerja & $(\%)$ & $\begin{array}{c}\text { Tidak } \\
\text { Bekerja }\end{array}$ & $(\%)$ \\
\hline 1. & Simplisia & & & & \\
2. & Serbuk & 10 & 27,7 & 17 & 47,2 \\
2. & Pil & 6 & 16,6 & 2 & 5,5 \\
3. & Kapsul & 0 & 0 & 0 & 0 \\
4. & Tablet & 0 & 0 & 1 & 2,7 \\
5. & Cairan & 0 & 0 & 0 & 0 \\
6. & Obat & 9 & 25,0 & 2 & 5,5 \\
& Dalam & & & & \\
\hline
\end{tabular}

Obat Tradisional berdasarkan karakteristik responden.

a. Pekerjaan

Responden yang tidak bekerja mayoritas menggunakan bentuk sediaan berupa simplisia sebanyak 17 responden $(47,2 \%)$, sedangkan responden yang bekerja mayoritas juga menggunakan 
bentuk sediaan berupa simplisia yakni 10 responden $(27,7 \%)$.

\section{Tabel 5}

Karakteristik ibu yang menggunakan bentuk sediaan tanaman obat tradisional untuk meningkatkan nafsu makan pada balita umur (24-59) bulan berdasarkan pekerjaan di Wilayah Desa Baran, Cawas, Klaten.

\begin{tabular}{clcc}
\hline No & $\begin{array}{c}\text { Bentuk } \\
\text { Sediaan }\end{array}$ & $\begin{array}{c}\text { Jumlah } \\
\text { Responden }\end{array}$ & $(\%)$ \\
\hline 1. & Simplisia & 27 & 75,0 \\
2. & Serbuk & 8 & 22,2 \\
3. & Pil & 0 & 0 \\
4. & Tapsul & 1 & 2,7 \\
5. & Cairlet & 0 & 0 \\
6. & Dalam Obat & 11 & 30,5 \\
\hline
\end{tabular}

b. Pendapatan Ekonomi

Responden yang memiliki pendapatan ekonomi kurang dari Upah Minimum Regional Kabupaten Klaten tahun 2014 yakni <Rp.1.026.000,mayoritas menggunakan bentuk sediaan berupa simplisia sebanyak 22 responden $(61,1 \%)$. Sedangkan responden dengan pendapatan ekonomi lebih atau sama dengan Upah Minimum Regional Kabupaten Klaten tahun 2014 paling banyak menggunakan bentuk sediaan berupa cairan obat dalam yaitu sebanyak 9 responden $(25 \%)$.

\section{Tabel 6}

Karakteristik ibu yang menggunakan tanaman obat tradisional untuk meningkatkan nafsu makan pada balita umur (24-59) bulan berdasarkan pendapatan ekonomi di Wilayah Desa Baran, Cawas, Klaten.

\begin{tabular}{llcccc}
\hline \multirow{2}{*}{ No } & $\begin{array}{l}\text { Bentuk } \\
\text { Sediaan }\end{array}$ & $\begin{array}{c}> \\
\text { umr }\end{array}$ & $(\%)$ & $\begin{array}{c}< \\
\text { umr }\end{array}$ & $(\%)$ \\
& Simplisia & & & & \\
1 & Serbuk & 5 & 13,8 & 22 & 61,1 \\
2 & Pil & 5 & 13,8 & 3 & 8,3 \\
3 & Kapsul & 0 & 0 & 0 & 0 \\
4 & Tablet & 0 & 0 & 1 & 2,7 \\
5 & Cairan & 0 & 0 & 0 & 0 \\
6 & Obat & 9 & 25,0 & 2 & 5,5 \\
& Dalam & & & & \\
\hline
\end{tabular}

Beberapa poin diatas, persentase dan jumlah responden jika ditotal maka hasilnya lebih dari 36 responden (100\%) karena masing-masing responden boleh memilih lebih dari satu bentuk sediaan yang digunakan.

5. Reaksi balita

Sebagian besar balita umur (24-59) bulan menunjukkan peningkatan nafsu makan setelah penggunaan tanaman obat tradisional yaitu 24 responden $(66,7 \%)$.

\section{Tabel 7}

Reaksi balita umur (24-59) bulan di Desa Baran, Cawas, Klaten setelah penggunaan tanaman obat tradisional untuk meningkatkan nafsu makan.

\begin{tabular}{llcc}
\hline No & $\begin{array}{c}\text { Reaksi } \\
\text { Balita }\end{array}$ & $\begin{array}{c}\text { Jumlah } \\
\text { Responden }\end{array}$ & $(\%)$ \\
\hline & Nafsu & & 66,7 \\
& makan & & 33,3 \\
1. & meningkat & 24 & \\
2. & Nafsu & 12 & \\
& makan & & \\
& tidak & & \\
& meningkat & & 100,0 \\
\hline
\end{tabular}

\section{PEMBAHASAN}

Ditinjau dari aspek pekerjaan, hasil penelitian menunjukkan bahwa mayoritas responden tidak bekerja dengan jumlah sebanyak 22 responden $(61,1 \%)$. Hal ini sesuai dengan pernyataan Supardi dan Andi (2007) bahwa proporsi penggunaaan tanaman obat tradisional pada responden yang mempunyai pekerjaan petani, nelayan dan tidak bekerja lebih tinggi daripada responden dengan pekerjaan lainnya.

Ditinjau dari aspek pendapatan ekonomi, hasil penelitian menunjukkan bahwa mayoritas responden memiliki pendapatan ekonomi kurang dari UMR (< Rp.1.026.000) Kabupaten Klaten tahun 2014 dengan jumlah sebanyak 26 responden $(72,2 \%)$. Hal ini sesuai dengan Kurniati (2013) dalam penelitiannya menyatakan bahwa penggunaan tanaman obat tradisional ada hubungan dengan pendapatan keluarga, karena semakin 
rendahnya pendapatan keluarga semakin tinggi penggunaan tanaman obat tradisional, hal ini dikarenakan harga yang lebih murah, bahan yang mudah didapat disekitar lingkungan tempat tinggal dan cara pengolahannya tidak rumit, sehingga dapat dibuat didapur sendiri tanpa memerlukan peralatan yang khusus dan biaya yang besar.

Jenis tanaman obat tradisional yang paling banyak digunakan responden untuk meningkatkan nafsu makan pada balita adalah temu hitam dengan jumlah 22 responden $(61,1 \%)$. Curcumin memiliki efek yang bagus pada usus halus. Khasiat Antispasmodic yang ditunjukkan oleh sodium curcuminate telah di teliti pada usus halus marmut. Aktivitas antiflatulent (carminative) telah di observasi secara in vivo dan in vitro pada eksperimen yang menggunakan tikus. Curcumin juga merangasang aktivitas dari lipase, sucrase dan maltase sejalan dengan ini maka dapat juga di ambil kesimpulan bahwa waktu pengosongan lambung menjadi lebih pendek. Dari aktivitas yang merangsang sistem pencernaan, sifatnya yang sebagai antiflatulent dimana gas akan menjadi lebih sedikit dan pencernaan lebih gampang terjadi.

Sebagian besar responden memilih untuk menggunakan bentuk sediaan tanaman obat tradisional berupa simplisia yaitu sebanyak 27 responden (75\%). Menurut Kurniati (2003) Tempat tinggal di pedesaan bermakna dengan penggunaan obat tradisional buatan sendiri atau jamu gendong. Penduduk yang tinggal di pedesaan lebih banyak menggunakan obat tradisional khususnya dalam bentuk simplisia.

Responden yang bekerja maupun tidak bekerja mayoritas menggunakan bentuk sediaan berupa simplisia. Hal ini sesuai dengan pernyataan Yuliatin (2007) bahwa pengolahan dari tanaman obat bagi kesehatan sangat mudah, sehingga siapapun yang ingin membuat jamu dari tanaman obat tersebut dapat melakukannya. Responden yang memiliki pendapatan ekonomi kurang dari Upah Minimum Regional Kabupaten Klaten tahun 2014 yakni < Rp.1.026.000 mayoritas menggunakan bentuk sediaan simplisia sebanyak 22 responden $(61,1 \%)$, sedangkan responden dengan pendapatan ekonomi lebih atau sama dengan Upah Minimum Regional Kabupaten Klaten tahun 2014 paling banyak menggunakan bentuk sediaan cairan obat dalam yaitu sebanyak 19 responden (25\%). Hal ini sesuai dengan pernyataan Glagah dkk (2010) Obat yang diolah dipabrik cenderung lebih mahal daripada membuat sendiri karena pengolahan di pabrik membutuhkan biaya yang tidak sedikit.

Berdasarkan hasil penelitian diketahui bahwa dari 36 responden yang memberikan tanaman obat tradisional untuk meningkatkan nafsu makan pada balita, 24 responden $(66,7 \%)$ menyatakan bahwa nafsu makan balita tersebut meningkat. Hal ini sesuai dengan pernyataan Handayani dan Maryani (2002) bahwa secara umum, cara kerja tanaman obat tradisional untuk meningkatkan nafsu makan pada anak adalah meningkatkan metabolisme, menekan atau menghambat asam lambung dan merangsang sekresi makanan sehingga meningkatkan nafsu makan.

\section{KESIMPULAN DAN SARAN}

Ditinjau dari karakteristik responden, terdapat $61,1 \%$ responden tidak bekerja dan $72,2 \%$ memiliki pendapatan kurang dari UMR (Rp.1.026.000). Jenis tanaman obat tradisional yang paling banyak digunakan adalah temu hitam dengan persentase $61,1 \%$. Bentuk sediaan yang paling banyak digunakan adalah simplisia dengan persentase $75 \%$. Responden yang tidak bekerja mayoritas menggunakan bentuk sediaan simplisia dengan persentase $47,2 \%$ dan responden yang 
bekerja mayoritas juga menggunakan bentuk sediaan simplisia dengan persentase $27,7 \%$. Responden yang memiliki pendapatan ekonomi kurang dari UMR (Rp.1.026.000) per bulan mayoritas menggunakan bentuk sediaan simplisia dengan persentase $61,1 \%$. Sedangkan responden dengan pendapatan ekonomi lebih atau sama dengan UMR paling banyak menggunakan bentuk sediaan cairan obat dengan persentase $25 \%$. Sebagian besar responden mengatakan nafsu makan balita meningkat setelah menggunakan tanaman obat tradisional dengan persentase $66,7 \%$.

Saran untuk penelitian ini adalah:

1. Bagi tenaga kesehatan khususnya bidan Desa Baran

Penggunaan bahan alam khususnya tanaman obat tradisional diharapkan bisa menjadi bahan pertimbangan dalam pemberian promosi kesehatan tentang peningkatan nafsu makan pada balita.

2. Bagi ibu yang memiliki balita

Diharapakan dapat melanjutkan menggunakan tanaman obat tradisional untuk meningkatkan nafsu makan pada balita tentunya dengan cara dan dosis yang tepat agar dapat memberikan efek yang cukup signifikan.

3. Bagi peneliti selanjutnya

Hasil penelitian ini dapat digunakan sebagai data dasar untuk penelitian tentang peningkatan nafsu makan balita menggunakan tanaman obat tradisional secara lebih luas dan mendalam antaralain menggali tentang pola dan cara penggunaan tanaman obat tradisional untuk meningkatkan nafsu makan pada balita.

\section{DAFTAR RUJUKAN}

Glagah, dkk. 2010. Kearifan Lokal ObatObatan di Indonesia. Laporan Mata Kuliah. Jurusan Antropologi ITB. Bandung.
Handayani.L dan Herti. 2002. Mengatasi Penyakit Pada Anak Dengan Ramuan Tradisional. Agro Media Pustaka. Jakarta.

KepMenKes RI No: 381/ Menkes/ SK/III/ 2007. Kebijakan Obat Tradisional Nasional. 27 Maret 2007. Departemen Kesehatan Republik Indonesia. Jakarta.

KepMenKes RI No: 661/ Menkes/ SK/ VII/ 1994. Persyaratan Obat Tradisional. Departemen Kesehatan Republik Indonesia. Jakarta.

Kurniati, Yeni. 2013. Faktor-Faktor Yang Berhubungan Dengan Penggunaan Obat Tradisional Bagi Ibu Nifas Di

Desa Bineh Krueng Kecamatan Tangan-Tangan Kabupaten Aceh Barat Daya. Karya Tulis Ilmiah. Program diploma STIKes U'budiyah Banda Aceh. Aceh

S.Thomas.A.N. 1992. Tanaman Obat Tradisional 2. Kanisius. Yogyakarta. Supardi.S dan Andi Susyanti.A.L. 2007.

Penggunaan Obat Tradisional Dalam Upaya Pengobatan Sendiri Di Indonesia (Analisis Data Susenas Tahun 2007). Pusat Penelitian dan Pengembangan Sistem dan Kebijakan Kesehatan. Jakarta.

Yuliatin. 2007. Sikap Ibu Rumah Tangga Pedesaan Terhadap Tanaman Obat Keluarga. Skripsi.Program Sarjana Jurusan Pertanian Universitas Muhammadiyah Malang. Malang. 